\title{
Apparent Diffusion Coefficient Value as a Biomarker for Detecting Muscle-Invasive and High-Grade Bladder Cancer: A Systematic Review
}

\author{
Shuichiro Kobayashi *(D), Kosuke Takemura and Fumitaka Koga (D)
}

Citation: Kobayashi, S.; Takemura, K.; Koga, F. Apparent Diffusion Coefficient Value as a Biomarker for Detecting Muscle-Invasive and High-Grade Bladder Cancer: A Systematic Review. Appl. Sci. 2022, 12, 1278. https://doi.org/10.3390/ app12031278

Academic Editor: Arnaldo Stanzione

Received: 26 December 2021

Accepted: 24 January 2022

Published: 25 January 2022

Publisher's Note: MDPI stays neutral with regard to jurisdictional claims in published maps and institutional affiliations.

Copyright: (C) 2022 by the authors. Licensee MDPI, Basel, Switzerland. This article is an open access article distributed under the terms and conditions of the Creative Commons Attribution (CC BY) license (https:// creativecommons.org/licenses/by/ $4.0 /)$.

\author{
Department of Urology, Tokyo Metropolitan Cancer and Infectious Diseases Center Komagome Hospital, \\ Tokyo 113-8677, Japan; takemura-urol@cick.jp (K.T.); f-koga@cick.jp (F.K.) \\ * Correspondence: shu_kobayashi@cick.jp
}

\begin{abstract}
Background: Several studies have investigated the potential role of the apparent diffusion coefficient (ADC) value of diffusion-weighted magnetic resonance imaging as a biomarker of highgrade and invasive bladder cancer. Methods: PubMed and the Cochrane Library were systematically searched in September 2021 to extract studies that evaluated the associations between ADC values, pathological T stage, and histological grade bladder cancers. The diagnostic performance of ADC values in detecting muscle-invasive bladder cancer (MIBC) and high-grade disease was systematically reviewed. Results: Six studies were included in this systematic review. MIBC showed significantly lower ADC values than non-muscle-invasive bladder cancer (NMIBC) in all six studies. The median (range) sensitivity, specificity, and area under the curve (AUC) of ADC values to detect MIBC among the four eligible studies were 73.5\% (68.8-90.0\%), 79.9\% (66.7-84.4\%), and 0.762 (0.730-0.884), respectively. Similarly, high-grade disease showed significantly lower ADC values than did low-grade disease in all four eligible studies. The median (range) sensitivity, specificity, and AUC of ADC values for detecting high-grade disease among the three eligible studies were $75.0 \%(73.0-76.5 \%), 95.8 \%$ (76.2-100\%), and $0.902(0.804-0.906)$, respectively. Conclusions: The ADC value is a non-invasive diagnostic biomarker for discriminating muscle-invasive and high-grade bladder cancer.
\end{abstract}

Keywords: apparent diffusion coefficient; bladder cancer; diffusion magnetic resonance imaging; neoplasm grading; neoplasm staging

\section{Introduction}

Bladder cancer is the most common malignancy of the urinary tract. Approximately $70 \%$ of bladder cancer cases are classified as non-muscle-invasive bladder cancer (NMIBC, tumor with T1 or a lower stage) [1]. Patients with low-grade NMIBC are usually managed conservatively with transurethral resection of the bladder tumor (TURBT) with or without intravesical therapy, and they show favorable survival outcomes. However, patients with high-grade NMIBC and muscle-invasive bladder cancer (MIBC, tumor with T2 or a higher stage) require more intensive therapies, and according to the European Association of Urology guidelines [2], those with high-grade NMIBC are recommended to undergo re-TURBT to rule out possible MIBC or residual disease, followed by intravesical Bacillus CalmetteGuérin instillation because of the high risk of recurrence and progression. The standard of care for patients with non-metastatic MIBC is radical cystectomy with perioperative systemic chemotherapy [3]. Despite intensive therapies, these patients are at a high risk of recurrence or metastasis, with a 5-year overall survival rate of approximately 50\% [4,5]. Thus, accurate assessment of the presence of MIBC and high-grade disease is essential for the appropriate management of patients with bladder cancer.

In clinical practice, TURBT specimens are used for the evaluation of the histological grade and T stage. However, fragmentation of tumor tissue and the effects of thermal cauterization hamper accurate histopathological diagnosis. Indeed, an understaging rate of $48 \%$ 
was reported among patients with clinical T1 disease who underwent radical cystectomy [6]. Hence, there is an unmet need for diagnostic methods other than TURBT-based histopathological examination in which MIBC and high-grade disease are accurately detected.

In current clinical practice, multiparametric magnetic resonance imaging (mpMRI) is the most accurate imaging modality for T staging of bladder cancer [7]. Recently, the Vesical Imaging-Reporting and Data System (VI-RADS) score utilizing mpMRI was introduced [8,9]. Validation studies have demonstrated the high accuracy of the VI-RADS score in diagnosing MIBC $[10,11]$. Among the imaging protocols that employ mpMRI, diffusion-weighted MRI (DW-MRI) is a functional imaging technique that allows quantification of the diffusion of tissue water molecules [12]. The apparent diffusion coefficient (ADC) quantitatively expresses the degree of diffusion. We previously reported that the ADC is a biomarker that reflects the histological grade and clinical T stage of bladder cancer $[13,14]$. Several other groups have also evaluated the association of ADC values with the histological grade and T stage of bladder cancer [15-26].

In this study, we performed a systematic review of all published studies to assess the role of ADC values in differentiating MIBC and high-grade bladder cancer from NMIBC and low-grade bladder cancer, respectively.

\section{Materials and Methods}

\subsection{Literature Search}

This study was conducted according to the preferred reporting items for systematic review and meta-analysis (PRISMA) statement [27]. The research question was as follows: Can ADC values differentiate MIBC and high-grade disease from NMIBC and low-grade disease, respectively? We performed a systematic search of the literature in PubMed, the Cochrane Library, and Embase for studies evaluating the associations between ADC values and the pathological $\mathrm{T}$ stage and grade in bladder cancer patients. The search was performed on 14 January 2022, using the following research terms: ((bladder OR urothelial OR transitional) AND (cancer OR carcinoma)) AND (("magnetic resonance imaging" OR "MRI") AND ("DWI" OR "diffusion-weighted" OR "apparent diffusion coefficient")) AND ("grade" OR "stage" OR "aggressive"). The literature search was performed by two authors (initially by S.K. and double-checked by K.T.). Searches were performed for studies published between 2000 and 2021, and those not published in English were excluded. A bibliographic database (EndNote X6; Thomas Reuters, New York, NY, USA) was used to filter out duplicate articles.

\subsection{Study Selection}

Figure 1 shows the PRISMA diagram outlining the study selection process. The studies were initially screened based on their title and abstract. Subsequently, the full texts were retrieved and evaluated for eligibility. Disagreements between investigators were resolved through discussions. Study eligibility was determined using the PICOS (participants, intervention, comparator, outcome, and study design) approach [28]. We included studies that met the following PICOS criteria: (P) participants had bladder cancer, (I) ADC values were calculated using DW-MRI, $(C)$ the pathological results of TURBT or cystectomy specimens were used as the reference standard, and (OS) the pathological T stage and histological grade were reported. The following publications were excluded from the study: (i) case reports and those with a study population consisting of fewer than 10 patients, (ii) publication types other than a research article (i.e., review articles, editorials, or letters to the editor), and (iii) studies lacking information on either T stage or histological grade. When two or more studies were published from the same institution and their study periods overlapped, the latest study with more patients was adopted for systematic review. 


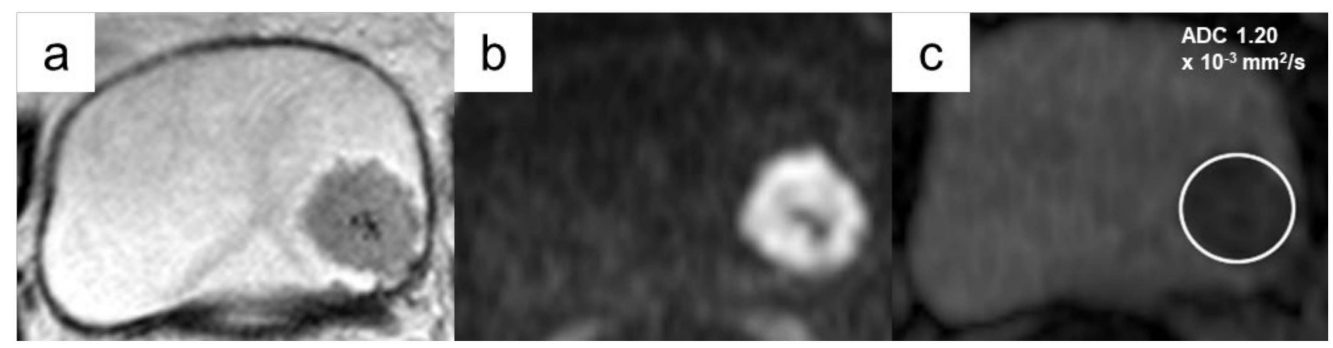

Figure 1. A patient with low grade, non muscle invasive (pTa) urothelial carcinoma of the bladder. (a) T2-weighted image. (b) Diffusion-weighted image. (c) Apparent diffusion coefficient value of the tumor $\left(1.20 \times 10^{-3} \mathrm{~mm}^{2} / \mathrm{s}\right)$.

\subsection{Data Extraction}

The primary outcomes are to systematically review the diagnostic performance of $A D C$ values in differentiating MIBC from NMIBC and high-grade disease from low-grade disease. We extracted data on study design, study period, the number of patients or tumors, demographics of patients and tumors including pathological $\mathrm{T}(\mathrm{pT})$ stage and histological grade, surgical modalities utilized to obtain tumor specimens for pathological diagnosis, magnet strength, and $b$ values used to calculate ADC values for all eligible studies. We further extracted data on the associations of ADC values with pT stage and histological grade. Sensitivity, specificity, and area under the curve (AUC) using the optimal cutoff ADC values were also extracted. Median (range) sensitivity, specificity, and AUC among eligible studies were obtained by calculating median values of those reported in each study. Because TURBT specimens were used for pathological diagnosis in most patients included in this review and the presence or absence of muscle invasion (pT2) is critical for decision making regarding therapeutic strategies, the $\mathrm{pT}$ stage was dichotomized as NMIBC $(\leq \mathrm{pT} 1)$ and MIBC $(\geq \mathrm{pT} 2)$ in this study. The representative cases of NMIBC and MIBC are shown in Figures 1 and 2, respectively.

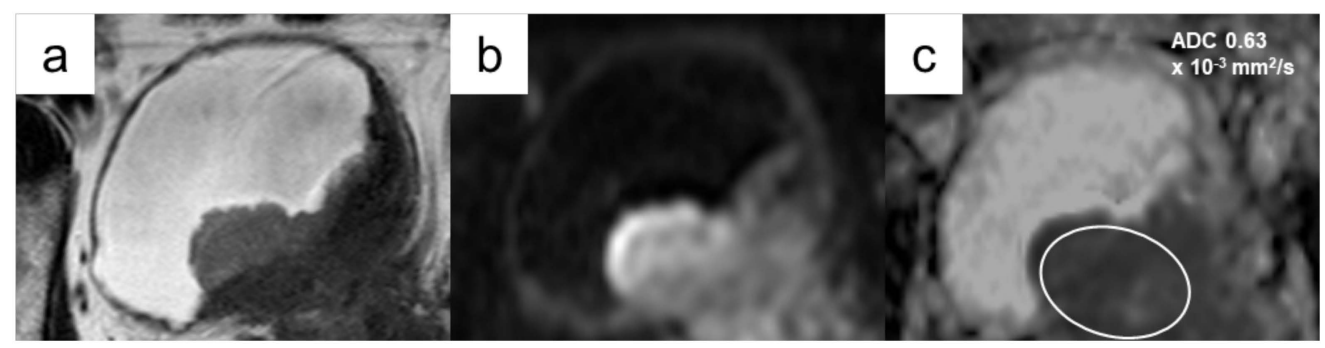

Figure 2. A patient with muscle-invasive bladder cancer (high-grade urothelial carcinoma, cT3b). (a) T2-weighted image. (b) Diffusion-weighted image. (c) Apparent diffusion coefficient value of the tumor $\left(0.63 \times 10^{-3} \mathrm{~mm}^{2} / \mathrm{s}\right)$.

\subsection{Quality Assessment}

We assessed the quality of the studies using the revised tool for the quality assessment of diagnostic accuracy studies 2 (QUADAS-2) [29]. Four domains, namely patient selection, index test, reference standard, and flow and timing, were scored, and all domains were assessed in terms of the risk of bias. Quality assessment was performed by the two reviewers, as described above, and disagreements were resolved by discussion to reach a consensus.

\section{Results}

\subsection{Literature Search}

The details of the search and article selection process are summarized in Figure 3. The literature search initially yielded 240 articles, of which 18 were included after the screening of titles and abstracts. After a full-text review of these studies, nine were excluded because associations between the ADC values and either the grade or T stage were not evaluated, 
and three were excluded due to overlapping study populations. Finally, six eligible studies including 550 patients with bladder cancer were reviewed for further analyses.

Identification of studies via databases and registers

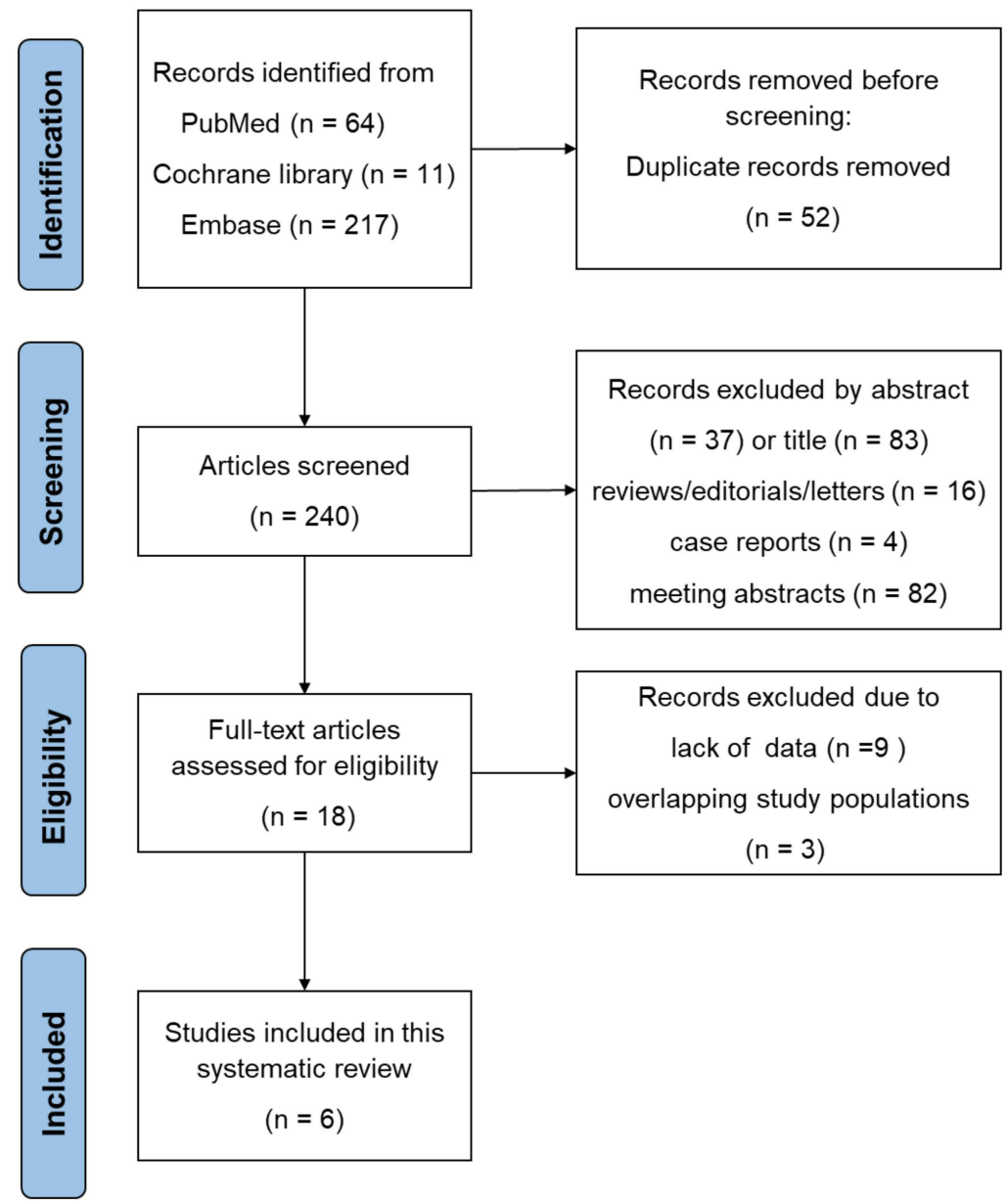

Figure 3. Flow chart of the literature search and article selection for present systematic review.

\subsection{Study Characteristics}

The characteristics of the six studies selected for this systematic review are listed in Table 1. These studies were published between 2013 and 2021, and three studies were prospective. Five studies $[13,16-18,20]$ primarily evaluated the associations between ADC values and clinicopathological parameters, and one study evaluated the feasibility of fractional order calculus (FROC) parameters [26]. Histological grades were categorized as low or high according to the 2004 World Health Organization/International Society of Urological Pathology classification in three studies. The surgical modalities used to obtain specimens for pathological evaluation included TURBT, partial cystectomy, and radical cystectomy in $485(88 \%), 4(1 \%)$, and $63(11 \%)$ cases, respectively. No significant difference was found in the distribution of gender, histological grade, and pT category among the eligible studies. 
Table 1. Summary of six studies included in a systematic review.

\begin{tabular}{|c|c|c|c|c|c|c|c|c|c|c|c|c|}
\hline \multirow{2}{*}{$\begin{array}{c}\text { Author } \\
\text { [Reference No.] }\end{array}$} & \multirow{2}{*}{ Year } & \multirow{2}{*}{ Country } & \multirow{2}{*}{ Study Period } & \multirow{2}{*}{ Study Design } & \multirow{2}{*}{$\begin{array}{c}\text { Age, } \\
\text { Mean (Range) }\end{array}$} & \multirow{2}{*}{$\begin{array}{l}\text { No. Patients } \\
\text { (\%, Female) }\end{array}$} & \multirow{2}{*}{ No. BT } & \multirow{2}{*}{$\begin{array}{l}\text { Magnet } \\
\text { Strength }\end{array}$} & \multirow{2}{*}{$\begin{array}{l}\text { b Value } \\
\text { (Number) }\end{array}$} & \multicolumn{2}{|c|}{$\begin{array}{c}\text { Pathological Findings } \\
\text { (No. Patients) }\end{array}$} & \multirow{2}{*}{$\begin{array}{l}\text { Surgical Modalities to } \\
\text { Obtain Specimens }\end{array}$} \\
\hline & & & & & & & & & & Grade & pT Category & \\
\hline $\begin{array}{l}\text { Feng } \\
{[26]}\end{array}$ & 2021 & China & 2014-2019 & Prospective & $\begin{array}{c}60 \\
(37-79)\end{array}$ & $\begin{array}{l}58 \\
(12)\end{array}$ & 58 & $3.0 \mathrm{~T}$ & $\begin{array}{c}0-3600 \\
(16)\end{array}$ & $\begin{array}{l}\text { Low (21) } \\
\text { High (37) }\end{array}$ & $\begin{array}{l}\text { NMIBC (33) } \\
\text { MIBC (25) }\end{array}$ & $\begin{array}{l}\text { TUR (30) } \\
\text { PC (4) } \\
\text { RC (24) }\end{array}$ \\
\hline $\begin{array}{l}\text { Fujimura } \\
{[20]}\end{array}$ & 2016 & Japan & 2009-2013 & Retrospective & $\begin{array}{c}73 \\
(42-95)\end{array}$ & $\begin{array}{l}114 \\
(24)\end{array}$ & NA & $1.5 \mathrm{~T}$ & $\begin{array}{l}0,1000 \\
(2)\end{array}$ & $\begin{array}{l}\text { G1 (9) } \\
\text { G2 (48) } \\
\text { G3 (57) }\end{array}$ & $\begin{array}{l}\text { NMIBC (83) } \\
\text { MIBC (31) }\end{array}$ & TUR (114) \\
\hline $\begin{array}{l}\text { Yamada } \\
\text { [18] }\end{array}$ & 2014 & Japan & 2006-2013 & Retrospective & $\begin{array}{c}72 \\
(38-90)\end{array}$ & $\begin{array}{l}160 \\
(38)\end{array}$ & 99 & $1.5 \mathrm{~T}$ & $\begin{array}{l}0,1000 \\
\quad(2)\end{array}$ & $\begin{array}{l}\text { Low (31) } \\
\text { High (129) }\end{array}$ & $\begin{array}{l}\text { NMIBC (125) } \\
\text { MIBC (35) }\end{array}$ & $\begin{array}{l}\text { TUR (129) } \\
\text { RC (31) }\end{array}$ \\
\hline $\begin{array}{l}\text { Sevcenco } \\
{[17]}\end{array}$ & 2014 & Austria & 2012-2013 & Prospective & NA & $\begin{array}{l}49 \\
(20)\end{array}$ & 43 & $3.0 \mathrm{~T}$ & $\begin{array}{c}50-1000 \\
(3)\end{array}$ & $\begin{array}{l}\text { Low (24) } \\
\text { High (19) }\end{array}$ & $\begin{array}{l}\text { NMIBC (33) } \\
\text { MIBC (10) }\end{array}$ & TUR (51) \\
\hline $\begin{array}{l}\text { Kobayashi } \\
{[14]}\end{array}$ & 2014 & Japan & 2007-2011 & Prospective & $\begin{array}{c}68 \\
(38-88)\end{array}$ & $\begin{array}{l}132 \\
(23)\end{array}$ & 132 & $1.5 \mathrm{~T}$ & $\begin{array}{l}0-2000 \\
(4)\end{array}$ & $\begin{array}{l}\text { G1 (2) } \\
\text { G2 (67) } \\
\text { G3 (63) }\end{array}$ & $\begin{array}{l}\text { NMIBC (81) } \\
\text { MIBC (51) }\end{array}$ & TUR (132) \\
\hline $\begin{array}{c}\text { Rosenkrantz } \\
{[16]}\end{array}$ & 2013 & USA & NA & Retrospective & NA & $\begin{array}{l}37 \\
\text { (NA) }\end{array}$ & 37 & $1.5 \mathrm{~T}$ & $\begin{array}{l}0-800 \\
(3)\end{array}$ & NA & $\begin{array}{l}\text { NMIBC (21) } \\
\text { MIBC (16) }\end{array}$ & $\begin{array}{l}\text { TUR (29) } \\
\text { RC (8) }\end{array}$ \\
\hline
\end{tabular}

BT, bladder tumor; MIBC, muscle-invasive bladder cancer; NMIBC, non-muscle-invasive bladder cancer; PC, partial cystectomy, RC; radical cystectomy; TUR, transurethral resection. 


\subsection{Quality Assessment}

The distribution of the risk of bias in the six studies is presented in Figure 4. All studies had a low risk of bias in patient selection and index test domains. For the reference standard domain, three studies had an unclear risk of bias because they did not indicate whether radiologists were blinded to the histopathological findings $[14,16,18]$. For the flow and timing domains, three studies had an unclear risk of bias due to the unknown interval between MRI and pathology tests. None of the studies presented with concerns regarding the applicability to answer the research questions.

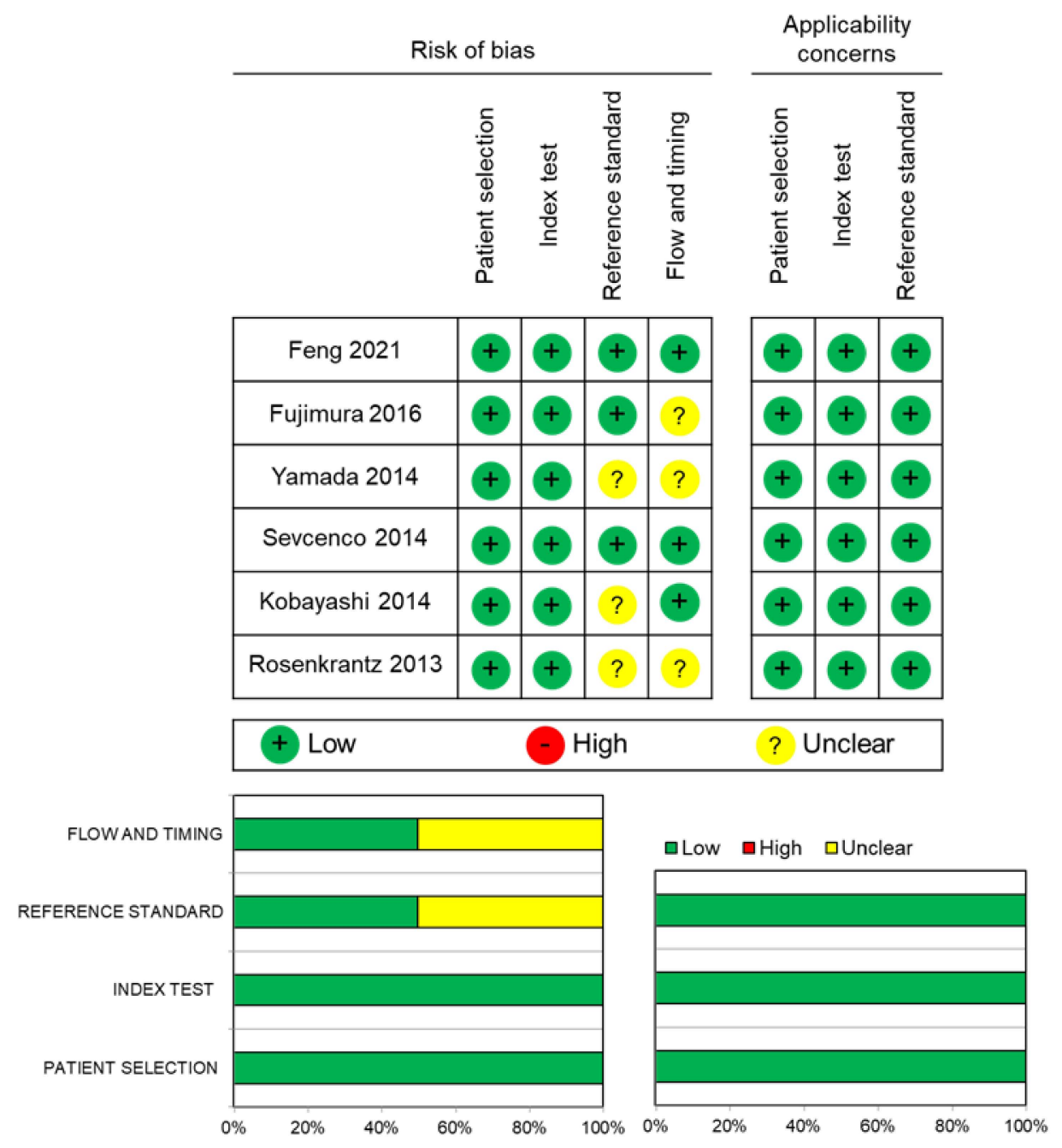

Figure 4. Risk of bias and applicability concerns summary: review authors' judgments about each domain for included studies according to revised quality assessment of diagnostic accuracy study 2 (QUADAS-2).

\subsection{Data Analysis}

3.4.1. Diagnostic Performance of ADC Values to Differentiate MIBC from NMIBC

ADC values were significantly lower in MIBC than in NMIBC in all studies (Table 2). Kobayashi et al. demonstrated significant differences in ADC values between Ta and T1 disease and between T1 and T2 disease [14]. Four studies provided the sensitivity and specificity of ADC values to diagnose MIBC. Cutoff ADC values were determined using the point closest to the upper-left corner of the ROC curves in four studies $[16,17,20,26]$. The median (range) sensitivity, specificity, and AUC for the diagnosis of MIBC were $73.5 \%$ (68.8-90.0\%), 79.9\% (66.7-84.4\%), and 0.762 (0.730-0.884), respectively. Feng et al. showed that FROC parameters yielded a significantly higher specificity (85\%) than ADC values $(67 \%)$ for distinguishing MIBC from NMIBC [26]. The performance of VI-RADS to diagnose 
MIBC improved from $88 \%$ to $90 \%$ in diagnostic accuracy and from 0.859 to 0.931 in the AUC when combined with FROC parameters [26].

Table 2. Diagnostic performance of ADC values to differentiate MIBC from NMIBC.

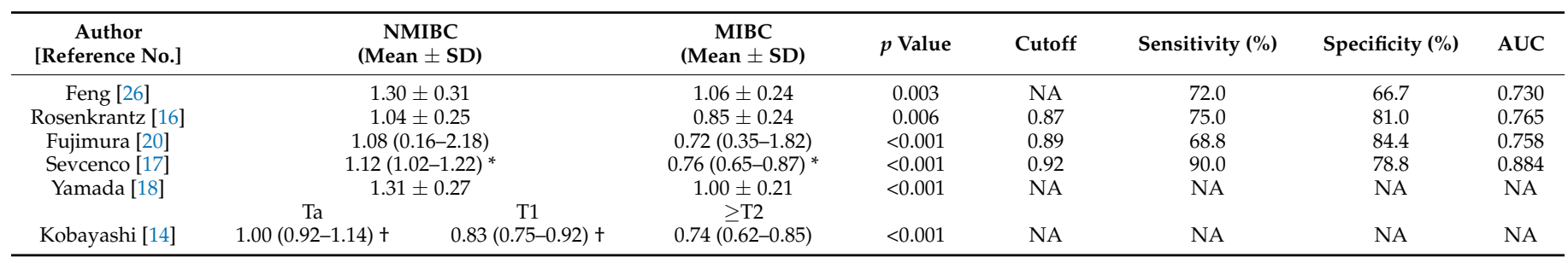

* mean $(95 \% \mathrm{CI}),+$ median (IQR). AUC, area under curve; MIBC, muscle-invasive bladder cancer; NMIBC, non-muscle-invasive bladder cancer; $\mathrm{SD}$, standard deviation.

\subsubsection{Diagnostic Performance of ADC Values to Differentiate High-Grade Disease from} Low-Grade Disease

The ADC values were significantly lower in high-grade disease than in low-grade disease in all four eligible studies (Table 3). Two other studies demonstrated significant differences in ADC values between diseases with histological grades 1, 2, and 3 . The median (range) sensitivity, specificity, and AUC to diagnose high-grade disease were $75.0 \%$ $(73.0-76.5 \%), 95.8 \%(76.2-100 \%)$, and $0.902(0.804-0.906)$, respectively, among the three eligible studies.

Table 3. Diagnostic performance of ADC value to differentiate high-grade disease from low-grade disease.

\begin{tabular}{|c|c|c|c|c|c|c|c|c|}
\hline \multirow[t]{2}{*}{$\begin{array}{c}\text { Author } \\
\text { [Reference No.] }\end{array}$} & \multicolumn{3}{|c|}{$\begin{array}{c}\text { Grade } \\
(\text { Mean } \pm \text { SD) }\end{array}$} & \multirow[t]{2}{*}{$p$ Value } & \multirow[t]{2}{*}{ Cutoff } & \multirow[t]{2}{*}{ Sensitivity (\%) } & \multirow[t]{2}{*}{ Specificity (\%) } & \multirow[t]{2}{*}{ AUC } \\
\hline & Low-grade & & High-grade & & & & & \\
\hline Feng [26] & $1.40 \pm 0.26$ & & $1.08 \pm 0.27$ & $<0.001$ & NA & 73.0 & 76.2 & 0.804 \\
\hline Rosenkrantz [16] & $1.35 \pm 0.28$ & & $0.92 \pm 0.24$ & 0.023 & 1.03 & 76.5 & 100.0 & 0.902 \\
\hline Yamada [18] & $1.58 \pm 0.21$ & & $1.20 \pm 0.27$ & $<0.001$ & NA & NA & NA & NA \\
\hline Sevcenco [17] & $1.23(1.15-1.32)$ * & & $0.79(0.69-0.88) *$ & $<0.001$ & 0.92 & 75.0 & 95.8 & 0.906 \\
\hline & Grade 1 & Grade 2 & Grade 3 & & & & & \\
\hline Fujimura [20] & $1.41(0.68-2.00)+$ & $1.15(0.16-2.10)+$ & $0.74(0.17-2.18) \dagger$ & $<0.001$ & NA & NA & NA & NA \\
\hline Kobayashi [14] & $1.00(0.92-1.14)+$ & $0.83(0.75-0.92)+$ & $0.74(0.62-0.85)+$ & $<0.001$ & NA & NA & NA & NA \\
\hline
\end{tabular}

\section{Discussion}

This systematic review demonstrated significantly lower ADC values in MIBC and high-grade disease than in NMIBC and low-grade disease, respectively. The median AUCs for detecting MIBC and high-grade disease were 0.762 and 0.902 , respectively. These findings suggest the key role of ADC values in the detection of clinically aggressive bladder cancer. To the best of our knowledge, this study is the first systematic review of the role of ADC values in detecting MIBC and high-grade bladder cancer. The ADC is considered a biomarker that reflects the aggressiveness of bladder cancer.

Malignant tumors are characterized by increases in cellularity, microvascular circulation, and tortuosity of the extracellular space, which limits the diffusion of water molecules, leading to low ADC values [30]. These features in the tumor microenvironment are prominent in highly aggressive cancers. Bladder cancer is classified into two major pathological phenotypes in terms of clinical aggressiveness: low-grade papillary non-invasive tumor (pTa) and high-grade invasive disease (T1 or greater). The former has a low tendency to develop disease progression with favorable prognosis, whereas the latter frequently leads to muscle invasion or incurable metastatic disease with an adverse prognosis [31]. Our results suggest that lower $A D C$ values reflect the presence of a disease with an aggressive phenotype. Interestingly, the ADC values were inversely correlated with the KI-67 labeling index of MIBC, an indicator of cell proliferation [14]. Incorporation of ADC values into conventional preoperative $\mathrm{T}$ staging may help reduce understaging by performing appropriate diagnostic TURBT, contributing to the development of appropriate treatment strategies based on accurate histopathological diagnosis. 
Although the ADC is reportedly associated with the prognosis of patients with several malignancies such as breast cancer and gastric cancer [32,33], the prognostic role of the ADC has not yet been fully evaluated. Recent studies on bladder cancer have also reported the prognostic significance of ADC values in terms of disease-specific survival $[34,35]$. Another study showed that ADC values could predict sensitivity to chemoradiotherapy in patients with MIBC [36]. These findings suggest that the measurement of ADC values is helpful for counseling patients on prognosis and for considering a chemoradiation-based bladder-sparing strategy in MIBC patients. However, due to the exploratory findings derived from studies consisting of a relatively small number of patients, further studies are needed to validate and confirm the prognostic role of the ADC in bladder cancer patients.

Although the mono-exponential model is generally used to measure ADC values, blood flow in capillaries in a voxel of an MR image moves much faster than water molecule diffusion. As the b-value increases, the deviation from the mono-exponential decay becomes non-negligible. To overcome the intrinsic limitation of ADC values, non-monoexponential models, such as the intravoxel incoherent motion (IVIM) [37] and FROC [38] models, have been developed to resolve the variability of ADC values. IVIM can distinguish the incoherent motion of water molecules within capillaries from molecular diffusion in the extravascular space [39]. IVIM-derived parameters (D, $D^{*}$, and f) were generated using a biexponential model. Zhang et al. [40] reported that IVIM-derived parameters could predict the aggressiveness of bladder cancer according to pathologic phenotypes: low aggressiveness, Ta of any grade and T1 with low-grade; intermediate aggressiveness, T1 with high-grade; and high aggressiveness, T2-T4 with any grade. In their study, ADC values showed slightly better diagnostic abilities than the IVIM-derived parameters to predict aggressiveness of bladder cancer. Feng et al. [26] reported that FROC parameters, which describe anomalous diffusion processes in complex biological tissues [38], were useful in distinguishing MIBC from NMIBC and in predicting histological grade in bladder cancer, and they outperformed ADC values in predicting histological grade. The combination of these novel parameters with ADC values is expected to improve the accuracy of preoperative diagnosis.

The VI-RADS has recently been shown to be useful in differentiating MIBC from NMIBC [9]. Limitations of the VI-RADS include (i) inter-observer disagreement in VI-RADS score, (ii) its inability to evaluate lymphovascular invasion and histological variants, and (iii) the different results depending on cutoff VI-RADS scores [10,41]. Despite sharing the limitations of item (ii) with the VI-RADS and the lack of standardized cutoff values, the ADC exhibits high interobserver agreement due to its quantitative nature [42-44]. Sakamoto et al. reported that the incorporation of ADC values into the VI-RADS improved the accuracy of detecting MIBC [45]. Taken together with the case of FROC parameters [26], incorporation of functional imaging parameters appears to improve the diagnostic performance of the VI-RADS.

The present systematic review had several limitations. First, there were a limited number of publications on the study topics of interest, and some of the included studies lacked data on sensitivity, specificity, or the AUC. Second, TURBT was used as a surgical modality for evaluating histopathology in most patients included in this study. Since the muscle layer is sometimes insufficiently sampled at TURBT, understaging of MIBC may have occurred. Given the real-world practice in which diagnostic TURBT is performed in every case of MIBC, and given a subset of MIBC patients receive neoadjuvant chemotherapy prior to radical cystectomy, this limitation was acceptable from a practical point of view. Third, the cutoff ADC values for detecting MIBC and high-grade disease varied between the studies. This is an inherent limitation of the ADC because this parameter depends on MRI protocols, including the coil system, imager, vendor, and magnetic field strength [46,47]. Nishizawa et al. [48] proposed an internal standardization of the ADC and that internally standardized ADC values could help overcome incompatibilities across different institutions utilizing different MRI protocols. Standardization of cutoff ADC values for detecting aggressive bladder cancer is expected in the future. 


\section{Conclusions}

The ADC is a non-invasive diagnostic biomarker for discriminating muscle-invasive and high-grade bladder cancers and reflects the clinical aggressiveness of bladder cancer. The integration of ADC values, VI-RADS scores, and other quantitative parameters is expected to improve the accuracy of evaluating the clinical aggressiveness of bladder cancer.

Author Contributions: Conceptualization, S.K. and F.K.; methodology, S.K. and K.T.; software, S.K. and K.T.; validation, S.K. and F.K.; formal analysis, S.K.; investigation, S.K.; resources, S.K.; writing - original draft preparation, S.K.; writing - review and editing, S.K. and F.K.; visualization, S.K.; supervision, F.K.; project administration, F.K. All authors have read and agreed to the published version of the manuscript.

Funding: This systematic review received no external funding.

Institutional Review Board Statement: Not applicable.

Informed Consent Statement: Not applicable.

Conflicts of Interest: The authors declare no conflict of interest.

\section{References}

1. Sylvester, R.J.; van der Meijden, A.P.; Oosterlinck, W.; Witjes, J.A.; Bouffioux, C.; Denis, L.; Newling, D.W.; Kurth, K. Predicting recurrence and progression in individual patients with stage Ta T1 bladder cancer using EORTC risk tables: A combined analysis of 2596 patients from seven EORTC trials. Eur. Urol. 2006, 49, 466-475, discussion 475-477. [CrossRef] [PubMed]

2. Babjuk, M.; Burger, M.; Capoun, O.; Cohen, D.; Compérat, E.M.; Dominguez Escrig, J.L.; Gontero, P.; Liedberg, F.; Masson-Lecomte, A.; Mostafid, A.H.; et al. European Association of Urology Guidelines on Non-muscle-invasive Bladder Cancer (Ta, T1, and Carcinoma in Situ). Eur. Urol. 2022, 81, 75-94. [CrossRef]

3. Witjes, J.A.; Bruins, H.M.; Cathomas, R.; Compérat, E.M.; Cowan, N.C.; Gakis, G.; Hernández, V.; Linares Espinós, E.; Lorch, A.; Neuzillet, Y.; et al. European Association of Urology Guidelines on Muscle-invasive and Metastatic Bladder Cancer: Summary of the 2020 Guidelines. Eur. Urol. 2021, 79, 82-104. [CrossRef] [PubMed]

4. Stein, J.P.; Lieskovsky, G.; Cote, R.; Groshen, S.; Feng, A.C.; Boyd, S.; Skinner, E.; Bochner, B.; Thangathurai, D.; Mikhail, M.; et al. Radical cystectomy in the treatment of invasive bladder cancer: Long-term results in 1054 patients. J. Clin. Oncol. 2001, 19, 666-675. [CrossRef] [PubMed]

5. Giacalone, N.J.; Shipley, W.U.; Clayman, R.H.; Niemierko, A.; Drumm, M.; Heney, N.M.; Michaelson, M.D.; Lee, R.J.; Saylor, P.J.; Wszolek, M.F.; et al. Long-term Outcomes After Bladder-preserving Tri-modality Therapy for Patients with Muscle-invasive Bladder Cancer: An Updated Analysis of the Massachusetts General Hospital Experience. Eur. Urol. 2017, 71, 952-960. [CrossRef] [PubMed]

6. Ark, J.T.; Keegan, K.A.; Barocas, D.A.; Morgan, T.M.; Resnick, M.J.; You, C.; Cookson, M.S.; Penson, D.F.; Davis, R.; Clark, P.E.; et al. Incidence and predictors of understaging in patients with clinical T1 urothelial carcinoma undergoing radical cystectomy. BJU Int. 2014, 113, 894-899. [CrossRef] [PubMed]

7. Woo, S.; Suh, C.H.; Kim, S.Y.; Cho, J.Y.; Kim, S.H. Diagnostic performance of MRI for prediction of muscle-invasiveness of bladder cancer: A systematic review and meta-analysis. Eur. J. Radiol. 2017, 95, 46-55. [CrossRef]

8. Huang, L.; Kong, Q.; Liu, Z.; Wang, J.; Kang, Z.; Zhu, Y. The Diagnostic Value of MR Imaging in Differentiating T Staging of Bladder Cancer: A Meta-Analysis. Radiology 2018, 286, 502-511. [CrossRef]

9. Panebianco, V.; Narumi, Y.; Altun, E.; Bochner, B.H.; Efstathiou, J.A.; Hafeez, S.; Huddart, R.; Kennish, S.; Lerner, S.; Montironi, R.; et al. Multiparametric Magnetic Resonance Imaging for Bladder Cancer: Development of VI-RADS (Vesical Imaging-Reporting And Data System). Eur. Urol. 2018, 74, 294-306. [CrossRef]

10. Woo, S.; Panebianco, V.; Narumi, Y.; Del Giudice, F.; Muglia, V.F.; Takeuchi, M.; Ghafoor, S.; Bochner, B.H.; Goh, A.C.; Hricak, H.; et al. Diagnostic Performance of Vesical Imaging Reporting and Data System for the Prediction of Muscle-invasive Bladder Cancer: A Systematic Review and Meta-analysis. Eur. Urol. Oncol. 2020, 3, 306-315. [CrossRef]

11. Del Giudice, F.; Pecoraro, M.; Vargas, H.A.; Cipollari, S.; De Berardinis, E.; Bicchetti, M.; Chung, B.I.; Catalano, C.; Narumi, Y.; Catto, J.W.F.; et al. Systematic Review and Meta-Analysis of Vesical Imaging-Reporting and Data System (VI-RADS) InterObserver Reliability: An Added Value for Muscle Invasive Bladder Cancer Detection. Cancers 2020, 12, 2994. [CrossRef] [PubMed]

12. Bammer, R. Basic principles of diffusion-weighted imaging. Eur. J. Radiol. 2003, 45, 169-184. [CrossRef]

13. Kobayashi, S.; Koga, F.; Yoshida, S.; Masuda, H.; Ishii, C.; Tanaka, H.; Komai, Y.; Yokoyama, M.; Saito, K.; Fujii, Y.; et al. Diagnostic performance of diffusion-weighted magnetic resonance imaging in bladder cancer: Potential utility of apparent diffusion coefficient values as a biomarker to predict clinical aggressiveness. Eur. Radiol. 2011, 21, 2178-2186. [CrossRef] [PubMed] 
14. Kobayashi, S.; Koga, F.; Kajino, K.; Yoshita, S.; Ishii, C.; Tanaka, H.; Saito, K.; Masuda, H.; Fujii, Y.; Yamada, T.; et al. Apparent diffusion coefficient value reflects invasive and proliferative potential of bladder cancer. J. Magn. Reson. Imaging 2014, 39, 172-178. [CrossRef]

15. Rosenkrantz, A.B.; Mussi, T.C.; Spieler, B.; Melamed, J.; Taneja, S.S.; Huang, W.C. High-grade bladder cancer: Association of the apparent diffusion coefficient with metastatic disease: Preliminary results. J. Magn. Reson. Imaging 2012, 35, 1478-1483. [CrossRef]

16. Rosenkrantz, A.B.; Haghighi, M.; Horn, J.; Naik, M.; Hardie, A.D.; Somberg, M.B.; Melamed, J.; Xiao, G.Q.; Huang, W.C.; Taouli, B. Utility of quantitative MRI metrics for assessment of stage and grade of urothelial carcinoma of the bladder: Preliminary results. Am. J. Roentgenol. 2013, 201, 1254-1259. [CrossRef]

17. Sevcenco, S.; Ponhold, L.; Heinz-Peer, G.; Fajkovic, H.; Haitel, A.; Susani, M.; Shariat, S.F.; Szarvas, T.; Baltzer, P.A. Prospective evaluation of diffusion-weighted MRI of the bladder as a biomarker for prediction of bladder cancer aggressiveness. Urol. Oncol. 2014, 32, 1166-1171. [CrossRef]

18. Yamada, Y.; Kobayashi, S.; Isoshima, S.; Arima, K.; Sakuma, H.; Sugimura, Y. The usefulness of diffusion-weighted magnetic resonance imaging in bladder cancer staging and functional analysis. J. Cancer Res. Ther. 2014, 10, 878-882. [CrossRef]

19. Wang, H.J.; Pui, M.H.; Guo, Y.; Li, S.R.; Guan, J.; Zhang, X.L.; Cai, H.S. Multiparametric 3-T MRI for differentiating low-versus high-grade and category T1 versus T2 bladder urothelial carcinoma. Am. J. Roentgenol. 2015, 204, 330-334. [CrossRef]

20. Fujimura, M.; Sakamoto, S.; Sekita, N.; Takeuchi, N.; Nishikawa, R.; Suzuki, H.; Mikami, K.; Ichikawa, T. Apparent diffusion coefficient value for estimating clinicohistological factors in bladder cancer including infiltration style and lymphatic invasion. Springerplus 2016, 5, 848. [CrossRef]

21. Al Johi, R.S.; Seifeldein, G.S.; Moeen, A.M.; Aboulhagag, N.A.; Moussa, E.M.; Hameed, D.A.; Imam, H.M. Diffusion weighted magnetic resonance imaging in bladder cancer, is it time to replace biopsy? Cent. Eur. J. Urol. 2018, 71, 31-37.

22. Wang, Y.; Hu, D.; Yu, H.; Shen, Y.; Tang, H.; Kamel, I.R.; Li, Z. Comparison of the Diagnostic Value of Monoexponential, Biexponential, and Stretched Exponential Diffusion-weighted MRI in Differentiating Tumor Stage and Histological Grade of Bladder Cancer. Acad. Radiol. 2019, 26, 239-246. [CrossRef] [PubMed]

23. Li, H.; Liu, L.; Ding, L.; Zhang, Z.; Zhang, M. Quantitative Assessment of Bladder Cancer Reflects Grade and Recurrence: Comparing of Three Methods of Positioning Region of Interest for ADC Measurements at Diffusion-weighted MR Imaging. Acad. Radiol. 2019, 26, 1148-1153. [CrossRef] [PubMed]

24. Wang, Y.; Shen, Y.; Hu, X.; Li, Z.; Feng, C.; Hu, D.; Kamel, I.R. Application of R2* and Apparent Diffusion Coefficient in Estimating Tumor Grade and T Category of Bladder Cancer. Am. J. Roentgenol. 2020, 214, 383-389. [CrossRef]

25. Yuan, L.; Li, D.; Mu, D.; Zhang, X.; Kong, W.; Cheng, L.; Shu, X.; Zhang, B.; Wang, Z. Combined T2 SPAIR, Dynamic Enhancement and DW Imaging Reliably Detect T Staging and Grading of Bladder Cancer With 3.0T MRI. Front. Oncol. $2020,10,582532$. [CrossRef]

26. Feng, C.; Wang, Y.; Dan, G.; Zhong, Z.; Karaman, M.M.; Li, Z.; Hu, D.; Zhou, X.J. Evaluation of a fractional-order calculus diffusion model and bi-parametric VI-RADS for staging and grading bladder urothelial carcinoma. Eur. Radiol. 2021. [CrossRef]

27. Moher, D.; Liberati, A.; Tetzlaff, J.; Altman, D.G. Preferred reporting items for systematic reviews and meta-analyses: The PRISMA statement. PLoS Med. 2009, 6, e1000097. [CrossRef]

28. Knoll, T.; Omar, M.I.; Maclennan, S.; Hernández, V.; Canfield, S.; Yuan, Y.; Bruins, M.; Marconi, L.; Van Poppel, H.; N’Dow, J.; et al. Key Steps in Conducting Systematic Reviews for Underpinning Clinical Practice Guidelines: Methodology of the European Association of Urology. Eur. Urol. 2018, 73, 290-300. [CrossRef]

29. Whiting, P.F.; Rutjes, A.W.; Westwood, M.E.; Mallett, S.; Deeks, J.J.; Reitsma, J.B.; Leeflang, M.M.; Sterne, J.A.; Bossuyt, P.M. QUADAS-2: A revised tool for the quality assessment of diagnostic accuracy studies. Ann. Intern. Med. 2011, 155, 529-536. [CrossRef]

30. Padhani, A.R.; Liu, G.; Koh, D.M.; Chenevert, T.L.; Thoeny, H.C.; Takahara, T.; Dzik-Jurasz, A.; Ross, B.D.; Van Cauteren, M.; Collins, D.; et al. Diffusion-weighted magnetic resonance imaging as a cancer biomarker: Consensus and recommendations. Neoplasia 2009, 11, 102-125. [CrossRef]

31. Klaassen, Z.; Kamat, A.M.; Kassouf, W.; Gontero, P.; Villavicencio, H.; Bellmunt, J.; van Rhijn, B.W.G.; Hartmann, A.; Catto, J.W.F.; Kulkarni, G.S. Treatment Strategy for Newly Diagnosed T1 High-grade Bladder Urothelial Carcinoma: New Insights and Updated Recommendations. Eur. Urol. 2018, 74, 597-608. [CrossRef] [PubMed]

32. Jeh, S.K.; Kim, S.H.; Kim, H.S.; Kang, B.J.; Jeong, S.H.; Yim, H.W.; Song, B.J. Correlation of the apparent diffusion coefficient value and dynamic magnetic resonance imaging findings with prognostic factors in invasive ductal carcinoma. J. Magn. Reson. Imaging 2011, 33, 102-109. [CrossRef]

33. Giganti, F.; Orsenigo, E.; Esposito, A.; Chiari, D.; Salerno, A.; Ambrosi, A.; Albarello, L.; Mazza, E.; Staudacher, C.; Del Maschio, A.; et al Prognostic Role of Diffusion-weighted MR Imaging for Resectable Gastric Cancer. Radiology 2015, 276, 444-452. [CrossRef] [PubMed]

34. Rosenkrantz, A.B.; Obele, C.; Rusinek, H.; Balar, A.V.; Huang, W.C.; Deng, F.M.; Ream, J.M. Whole-lesion diffusion metrics for assessment of bladder cancer aggressiveness. Abdom. Imaging 2015, 40, 327-332. [CrossRef]

35. Sevcenco, S.; Maj-Hes, A.B.; Hruby, S.; Ponhold, L.; Heinz-Peer, G.; Rauchenwald, M.; Marszalek, M.; Klingler, H.C.; Polanec, S.; Baltzer, P.A.T. Apparent diffusion coefficient values obtained by unenhanced MRI predicts disease-specific survival in bladder cancer. Clin. Radiol. 2018, 73, 881-885. [CrossRef] [PubMed] 
36. Yoshida, S.; Koga, F.; Kobayashi, S.; Ishii, C.; Tanaka, H.; Tanaka, H.; Komai, Y.; Saito, K.; Masuda, H.; Fujii, Y.; et al. Role of diffusion-weighted magnetic resonance imaging in predicting sensitivity to chemoradiotherapy in muscle-invasive bladder cancer. Int. J. Radiat. Oncol. Biol. Phys. 2012, 83, e21-e27. [CrossRef]

37. Le Bihan, D.; Breton, E.; Lallemand, D.; Grenier, P.; Cabanis, E.; Laval-Jeantet, M. MR imaging of intravoxel incoherent motions: Application to diffusion and perfusion in neurologic disorders. Radiology 1986, 161, 401-407. [CrossRef]

38. Magin, R.L.; Abdullah, O.; Baleanu, D.; Zhou, X.J. Anomalous diffusion expressed through fractional order differential operators in the Bloch-Torrey equation. J. Magn. Reson. 2008, 190, 255-270. [CrossRef]

39. Dixon, W.T. Separation of diffusion and perfusion in intravoxel incoherent motion MR imaging: A modest proposal with tremendous potential. Radiology 1988, 168, 566-567. [CrossRef]

40. Zhang, M.; Chen, Y.; Cong, X.; Zhao, X. Utility of intravoxel incoherent motion MRI derived parameters for prediction of aggressiveness in urothelial bladder carcinoma. J. Magn. Reson. Imaging 2018, 48, 1648-1656. [CrossRef]

41. Carando, R.; Afferi, L.; Marra, G.; Krajewski, W.; Pagliarulo, V.; Abufaraj, M.; Xylinas, E.; Cathelineau, X.; Sanchez-Salas, R.; Moschini, M. The effectiveness of multiparametric magnetic resonance imaging in bladder cancer (Vesical Imaging-Reporting and Data System): A systematic review. Arab. J. Urol. 2020, 18, 67-71. [CrossRef] [PubMed]

42. Jiang, J.; Yin, J.; Cui, L.; Gu, X.; Cai, R.; Gong, S.; Xu, Y.; Ma, H.; Mao, J. Lung Cancer: Short-Term Reproducibility of Intravoxel Incoherent Motion Parameters and Apparent Diffusion Coefficient at 3T. J. Magn. Reson. Imaging 2018, 47, 1003-1012. [CrossRef] [PubMed]

43. Zhao, L.; Zhao, M.; Liu, J.; Yang, H.; Zhou, X.; Wen, C.; Li, G.; Duan, Y. Mean apparent diffusion coefficient in a single slice may predict tumor response to whole-brain radiation therapy in non-small-cell lung cancer patients with brain metastases. Eur. Radiol. 2021, 31, 5565-5575. [CrossRef] [PubMed]

44. Priola, A.M.; Priola, S.M.; Parlatano, D.; Gned, D.; Giraudo, M.T.; Giardino, R.; Ferrero, B.; Ardissone, F.; Veltri, A. Apparent diffusion coefficient measurements in diffusion-weighted magnetic resonance imaging of the anterior mediastinum: Inter-observer reproducibility of five different methods of region-of-interest positioning. Eur. Radiol. 2017, 27, 1386-1394. [CrossRef]

45. Sakamoto, K.; Ito, M.; Ikuta, S.; Nakanishi, Y.; Kataoka, M.; Takemura, K.; Suzuki, H.; Tobisu, K.-I.; Kamai, T.; Koga, F. Detection of Muscle-Invasive Bladder Cancer on Biparametric MRI Using Vesical Imaging-Reporting and Data System and Apparent Diffusion Coefficient Values (VI-RADS/ADC). Bladder Cancer 2020, 6, 161-169. [CrossRef]

46. Sasaki, M.; Yamada, K.; Watanabe, Y.; Matsui, M.; Ida, M.; Fujiwara, S.; Shibata, E. Variability in absolute apparent diffusion coefficient values across different platforms may be substantial: A multivendor, multi-institutional comparison study. Radiology 2008, 249, 624-630. [CrossRef]

47. Donati, O.F.; Chong, D.; Nanz, D.; Boss, A.; Froehlich, J.M.; Andres, E.; Seifert, B.; Thoeny, H.C. Diffusion-weighted MR imaging of upper abdominal organs: Field strength and intervendor variability of apparent diffusion coefficients. Radiology 2014, 270, 454-463. [CrossRef]

48. Nishizawa, T.; Yoshida, S.; Koga, F.; Tanaka, H.; Kaga, M.; Watanabe, K.; Fukushima, H.; Nakanishi, Y.; Yokoyama, M.; Ishioka, J.; et al. Standardization of the apparent diffusion coefficient value of bladder cancer across different centers: Applicability in predicting aggressive pathologic phenotypes. Clin. Imaging 2017, 44, 121-126. [CrossRef] 